


\title{
El arte conceptual como recurso educativo, a través de las obras de algunos artistas centroamericanos
}

\author{
The conceptual art as an educational resource, through the works of some central american artists
}

\author{
Alberto Flores Canet $^{1}$ \\ Recibido: 8/10/2015 / Aprobado: 1/11/2016
}

\begin{abstract}
Resumen
Se aborda el papel del arte en la sociedad y en particular en la educación, se aportan ideas sobre el valor del arte conceptual en algunas de sus variantes expresivas, así como las posibilidades de ser utilizado como recurso didáctico en la enseñanza de algunos cursos en los cuales se pretende -además- abrir una posibilidad de explorar las tendencias artísticas postmodernas a partir de las propuestas estéticas y vincularlas con la historia.

Se toma como ejemplo la obra de cuatro artistas, cuyos trabajos son dignos de analizar desde varios ángulos, ante sobre todo por ser confrontativos, contestatarios, por la profundidad de sus contenidos y su actualidad, los cuales pueden servir de punto de partida para incorporar en la educación o cuando menos en algunos procesos de enseñanza y de aprendizaje, ya que sus obras explican situaciones de los tiempos actuales, como pueden ser: la marginalidad, la pobreza, la discriminación, la género, la ambiente, la corrupción, entre otros.
\end{abstract}

Palabras clave: Arte, arte conceptual, arte costarricense, educación, artistas centroamericanos.

\section{Abstract}

This paper attempts to reflect on the role of art in society, particularly in education, and it contributes with ideas about the value of conceptual art in some of its expressive variants and possibilities of being used as an educational resource in which one can reflect on the contents of several important pieces of work and their authors, in this case, national artists and Central Americans, whose proposals are framed in reflection on identity, culture and those problems we face. Thus, four artists 'pieces of work are being analyzed from different perspectives and angles, especially, for being confrontational and rebellious. The depth of its contents and present have served as a starting point to incorporate into education or a teaching and learning process where these pieces of work explain situations of this century such as: marginalization, poverty, discrimination, gender, environment, corruption among others.

Key words: Art, conceptual art, Costa Rican art, education, Central American artists.

\section{Introducción}

Este trabajo intenta reflexionar sobre el papel del arte en la sociedad y en particular en la educación, para aportar ideas sobre el valor del arte conceptual en algunas de sus variantes expresivas, así como las posibilidades de ser utilizado como recurso didáctico en la enseñanza de algunos cursos. En estos espacio es posible reflexionar sobre los contenidos de algunas obras importantes y por supuesto de sus autores, en este caso sobre artistas nacionales y centroamericanos, cuyas propuestas están enmarcadas en la reflexión sobre la identidad, la cultura y los problemas sociales.

El trabajo pretende abrir una posibilidad de explorar las tendencias artísticas postmodernas a partir de las propuestas estéticas y vincularlas con la historia, desde varias interrogantes, como

1 Licenciado en Historia del Arte de la la Universidad La Habana. Departamento de Filosofía, Artes y Letras, Sede de Occidente, Universidad de Costa Rica. Correo electrónico: acanet44@hotmail.com 
el porqué se mira y utiliza frecuentemente como referencia a Europa o Estados Unidos cuando se desea ejemplificar algún acontecimiento histórico o estético, o por qué se usa el arte afianzado en una tradición y no se involucra con las expresiones artísticas actuales y de la región, si por miedo o desconocimiento, o las razones por las cuáles al hablar de arte solo se piensa en entretenimiento.

Muchos docentes, cuando utilizan obras de arte, es porque están señalados en los programas de estudio, o películas como relleno de algún contenido. Es importante recordar que el conocimiento no es solo científico, existen muchas formas de saber, y a través del arte se puede estimular el conocimiento, es decir, otra forma de aprender, desde un enfoque sistémico, donde el arte, como elemento importante de la sociedad en su conjunto y de la superestructura, aporta mucho a la comprensión propia del sujeto y del funcionamiento social, de manera que esto se visualice como un todo.

Un ejemplo de esto son los sucesos acontecidos durante la invasión napoleónica en España, los cuales fueron comprendidos mejor a través de los grabados de Goya." Los desastres de la guerra." o la masacre de Guernica, vista por Picasso.
Esas obras pueden servir de punto de partida para incorporarse en la educación o al menos en algunos procesos de enseñanza y aprendizajecon el fin de explicar situaciones actuales, como la marginalidad, la pobreza, la discriminación, el género, el ambiente, la corrupción entre otros. La utilización de estos lenguajes estéticos propiciaría un aprendizaje de acción, constructivo, vinculante y analítico que perdure, además de acercar a los estudiantes a las expresiones artísticas contemporáneas, por lo cual se democratiza el arte, que a pesar de estar para todos, cerca de todos, sigue siendo elitista.

Al mismo tiempo, la apreciación y comprensión del arte conceptual estimula su consumo, y su revalorización, en una época donde se premia lo barato, vacio de contenidos; así como se estimula la creatividad a través de la decodificación de los símbolos contenidos en las obras. El alumno se convierte en un constructor activo de su propio conocimiento, vinculándolo con la realidad social en que viven y que se constituyan en agentes críticos y trasformadores de esa realidad. La función discursiva de este tipo de arte está llamada a desempeñar un papel importante hoy, ya que se dirige a romper los
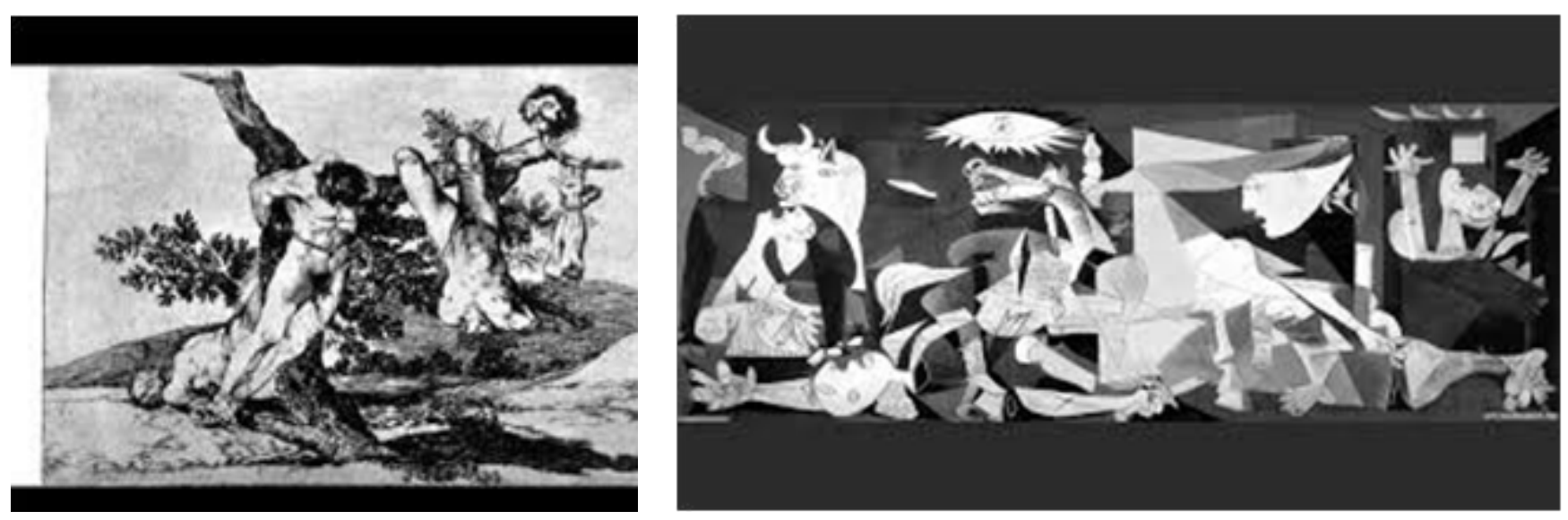

Francisco Goya. Los desastres de la guerra. 1814 Pablo Picasso. Guernica.1937. El mundo del arte. Edit. Oceano.2000.

Para ilustrar esta inquietud, se toman como ejemplos las obras de cuatro artistas, cuyos trabajos son dignos de analizar desde varios ángulos, sobre todo por ser confrontativos, contestatarios, por la profundidad de sus contenidos y su actualidad. centros de poder, al transformar su meta narrativa en un reflejo de las realidades, se separan de los discursos europeos o norteamericanos y, por tanto, puede servir como medio para llevar conocimiento y ser utilizado como recurso educativo. 


\section{Desarrollo}

\section{Arte conceptual: concepto e historia}

El arte conceptual, también conocido como, idea-art, information-art, e incluso como software-art, es un movimiento artístico en el que las ideas transmitidas son más importantes que la representación, el concepto por encima de los aspectos formales de la tradición, utilizados en el arte académico.Es una reacción contra el formalismo narrativo, y su desarrollo se enmarca en los años 60 del siglo XX, sin embargo en los primeros años de este siglo ha alcanzado su mayor práctica y difusión.

No obstante, las primeras muestras de este movimiento se remontan a inicios del siglo XX, entre 1917 y 1925, pues se desarrolla en Europa Occidental un movimiento artístico conocido como Dadaísmo, el cual es parte de la Vanguardia, cuyo discurso teórico, filosófico y estético estaba encaminado en romper con toda la tradición, se cuestionaba aspectos como el papel del arte, su función, y sobre todo quiénes califican las producciones artísticas como obras de arte. Todos estos cuestionamientos hicieron que este movimiento se considere como anti-arte o, lo que es lo mismo, antiacadémico.

\section{MANIFIESTO DADAISTA}

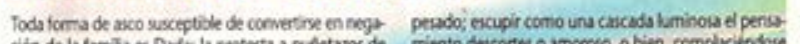

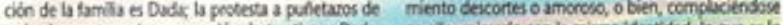

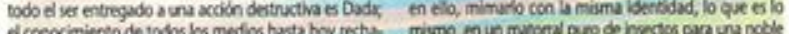

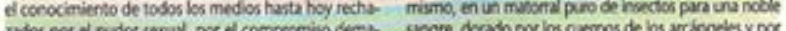

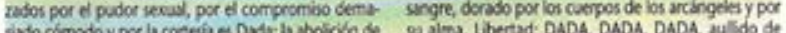

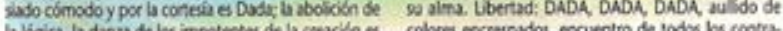

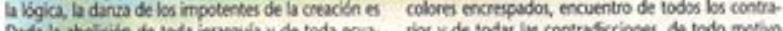

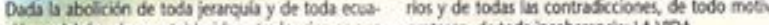
ón social de vioues etablecida entre los sienvos que

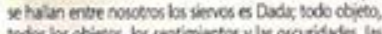

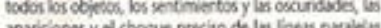
aparicones y ol chocue preciso de las liness purielas son medior de livch Dadry Dads; abolicion datias cutible en todo dios prodacto inmediato de la expontaneidat Dady sato elegante $y$ sin prejuicios de una armonis a otra eslers ropectoria of una palabra lanzada como un disco, grito sonoro; respelo de voder las individualdades en la momentines locura de caba uno de sers sectimion tos, serios o temerosos, tivides o ardentes vigo tosos, decifidos, entuias. tas despoir lis gropia ine is de vodo acceicio in?

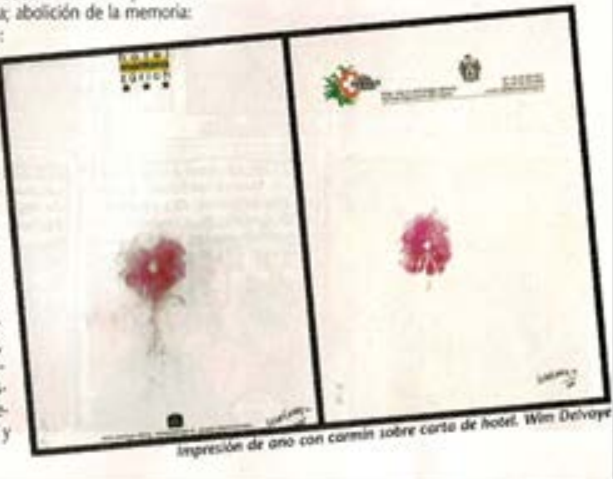

Manifiesto Dadaísta. 1918. Dada 1
Son grandes personalidades las que integran este grupo, cuyo manifiesto, está plagado de irreverencias hacia lo tradicional, entre estos artistas es importante destacar las obras de Marcel Duchamp y los llamados ready made; objetos apenas intervenidos, a los cuales se les niega su función original y se les atribuye de manera consciente un nuevo concepto, de manera que se convierten en obras de arte por decisión del propio artista.

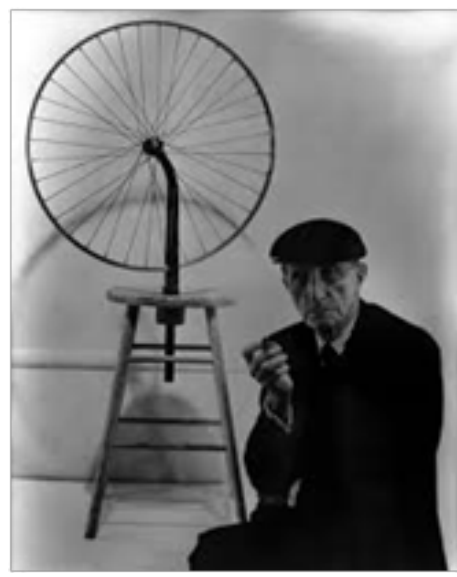

Marcel Duchapm. Rueda de bicicleta. 1913. El mundo del arte. Edit. Oceano.2000

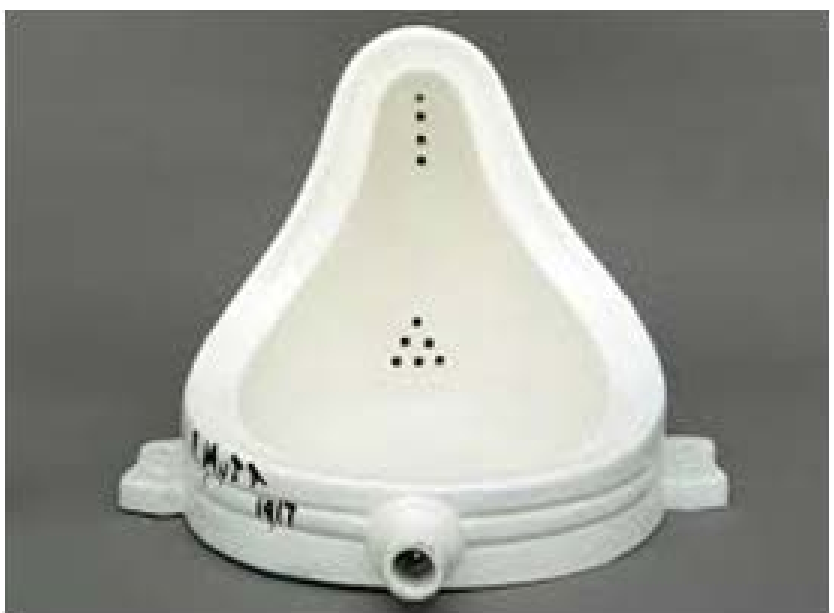

Marcel Duchapm. La fuente. 1917. El mundo del arte. Edit. Oceano.2000 


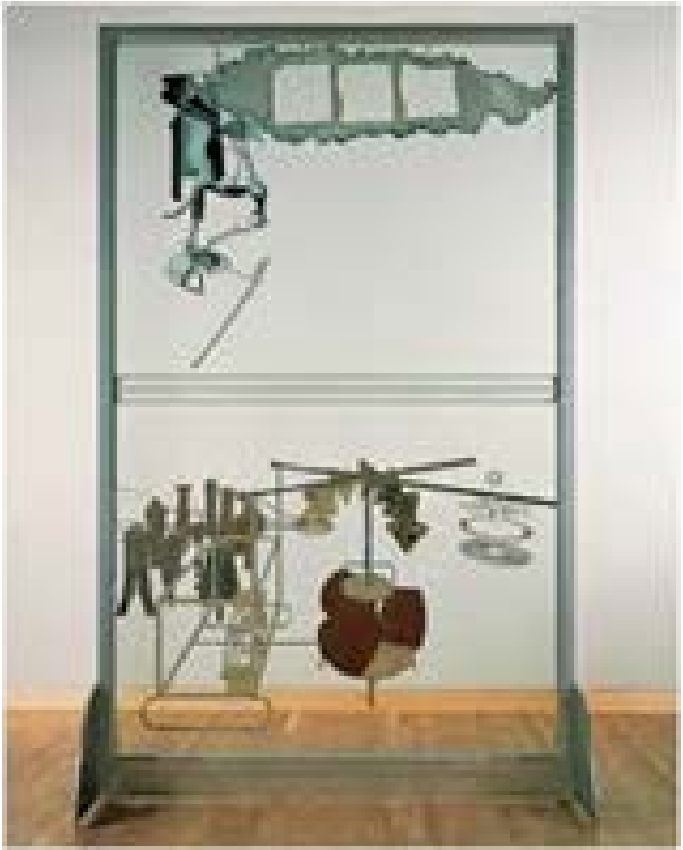

Marcel Duchapm. El gran vidrio. 1931. El mundo del arte. Edit. Oceano.2000.

El arte conceptual también recibe aportes del Cubismo, sobre todo del Cubismo Sintético, el cual introduce el collage como recurso expresivo. El artista Pablo R. Picasso, realiza algunas obras que representan ideas de algo, con materiales de desecho.

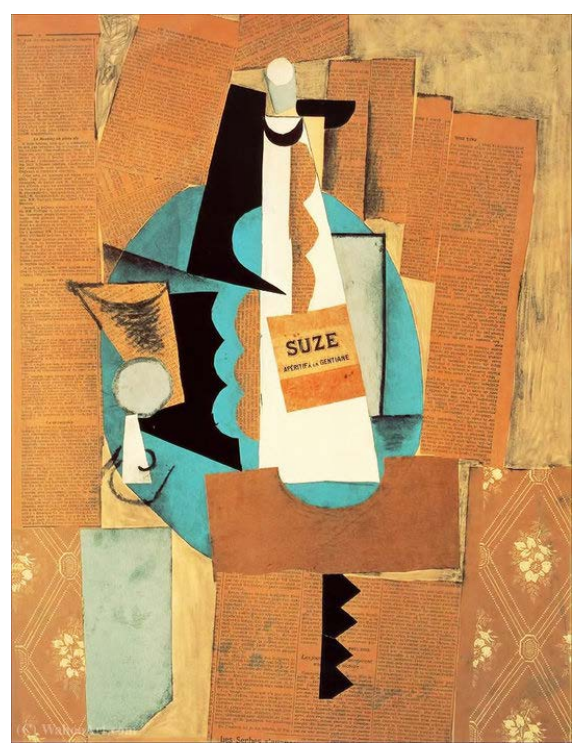

Pablo R. Picasso. Botella. 1924. Edit. Oceano.2000

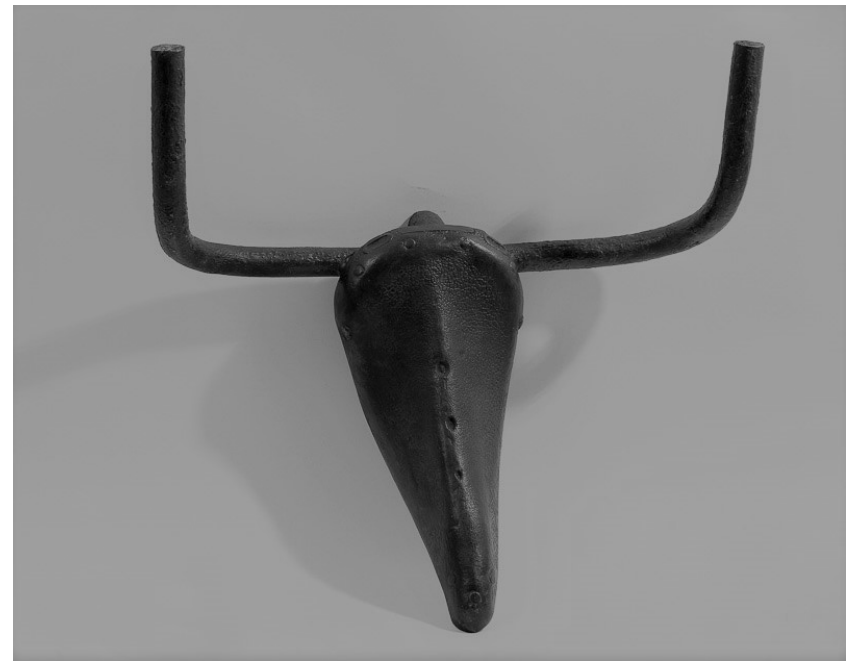

Pablo R. Picasso. La cabra. 1941.Edit. Oceano.2000.

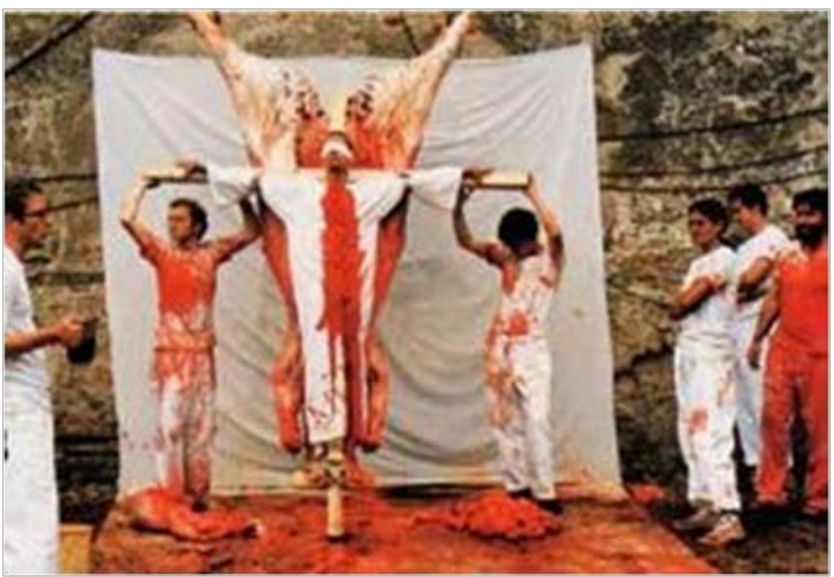

John Cage. Sacrificio. 2000. El arte y el hombre. Edit. Oceano. 2000 
Se ubica el nacimiento del arte conceptual casi al mismo tiempo en Estados Unidos y Europa. Su germen se encuentra en los problemas heredados después de la Segunda Guerra Mundial y el descontento con los postulados de la modernidad. Esas problemáticas permiten que los discursos del arte conceptual se vuelvan contestatarios, antiburgueses y críticos hacia el orden religioso, político y económico; se interesan por los problemas sociales, la defensa de la identidad cultural y contra las políticas neoliberales.

Ideológicamente, el arte conceptual es opuesto a la burguesía y al consumismo, induce a la acción y a la participación del espectador, provoca la reflexión y a la toma de conciencia en aspectos diversos, como la lucha por el medio ambiente, igualdad, género, etc. Dentro de sus característica fundamentales está su carácter efímero, como consecuencia de los postulados de la postmodernidad, se observan aspectos significativos como su relativismo, deconstruccionismo, diversidad explicativa y la existencia de pequeños relatos que declaran la libertad absoluta, tanto en lo que tiene que ver con la creatividad y la democratización del arte, porque manifiesta que nadie es dueño del arte.

Para expresarse, el arte conceptual muestra una variedad importante de lenguajes dentro de sus propias manifestaciones, como la fotografía, el performance, las instalaciones, el body art, el land art, el video-art, entre otros.
A partir de los años 80 del siglo XX, se revitaliza en todo el mundo el arte de ideas, particularmente en los principales centros culturales, en los eventos de carácter visual, como el Museo de arte moderno de Nueva York, Feria Internacional de arte Arco, en Madrid, Miami, Bienales como La Habana, Sao Paulo, entre otros; en casi todos ellos las obras presentadas son de carácter conceptual.

En el caso particular de Centroamérica, el arte conceptual se ha desarrollado de forma muy especial desde finales del siglo XX y en el presente siglo alcanza su madurez al destacarse las producciones de artistas de Guatemala y Costa Rica, con eventos como la Bienal Promérica de artes visuales del Itsmo centroamericano y las numerosas exposiciones, charlas, conferencias y proyecciones programadas en el Museo de arte y diseño contemporáneo y en la Galería Museo Teorética. En Costa Rica, la creación del Museo de arte y diseño contemporáneo, en el 1998 y posteriormente la Fundación Teorética se van a convertir en un referente absoluto, para exponer, divulgar, patrocinar, y estimular a los creadores del país y de toda la región; se ofrecen charlas, proyecciones de audiovisuales, poseen espacios para consultar material bibliográfico, visitas guiadas y eventos culturales, en su mayoría vinculados con el arte de conceptos.
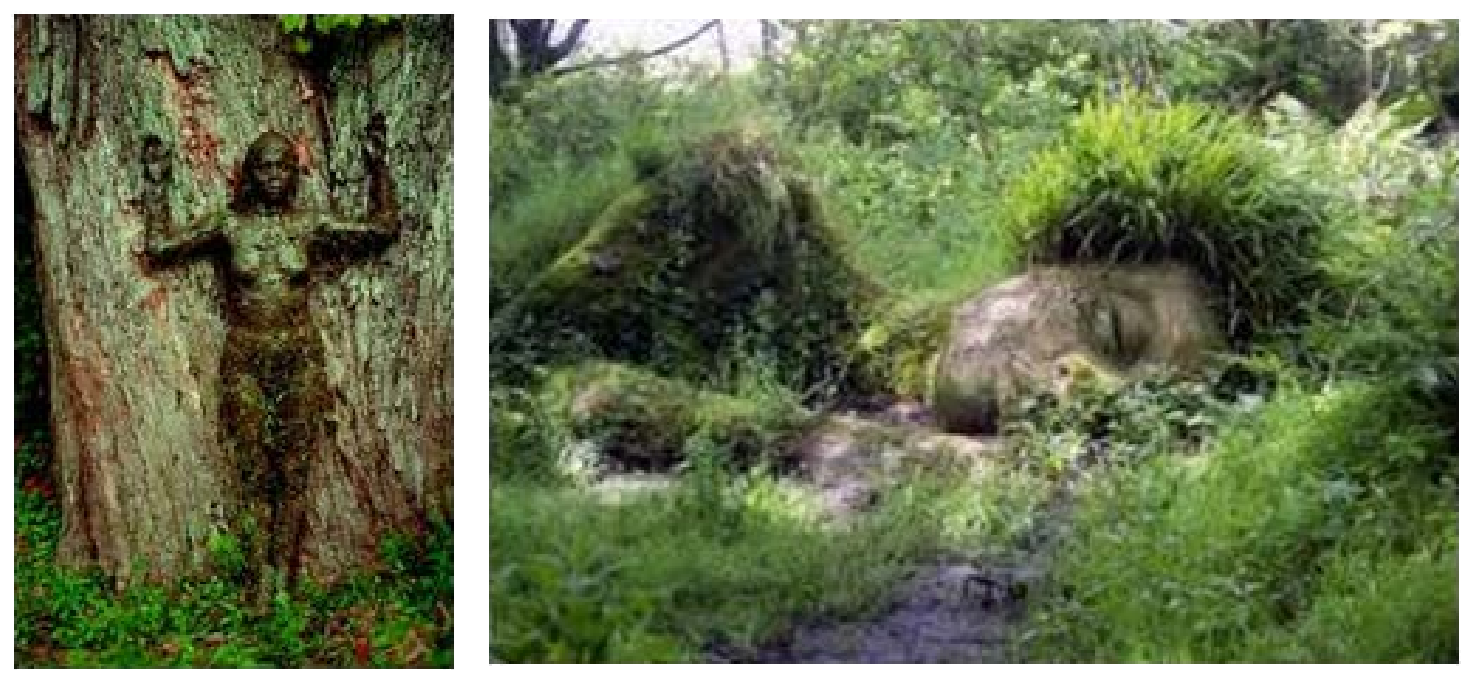

Ana Mendieta. Land art. Body art. El mundo del arte. Edit. Oceano.2000 


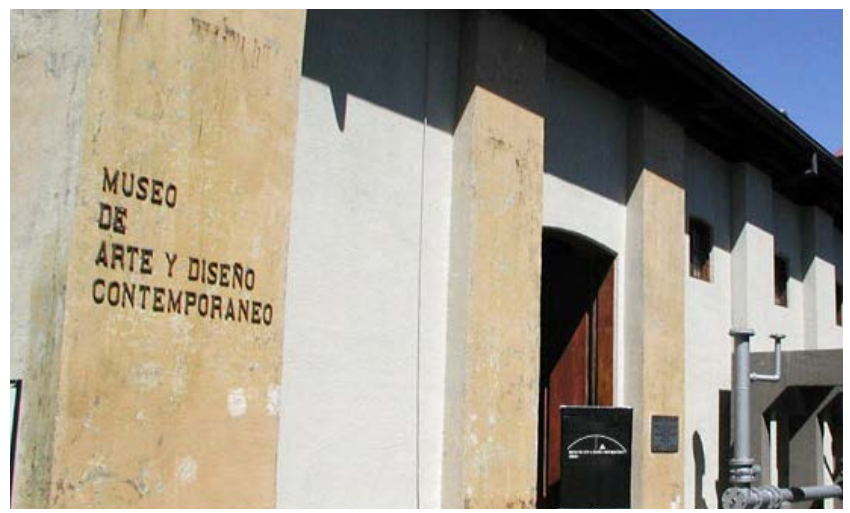

Museo de arte y diseño contemporáneo

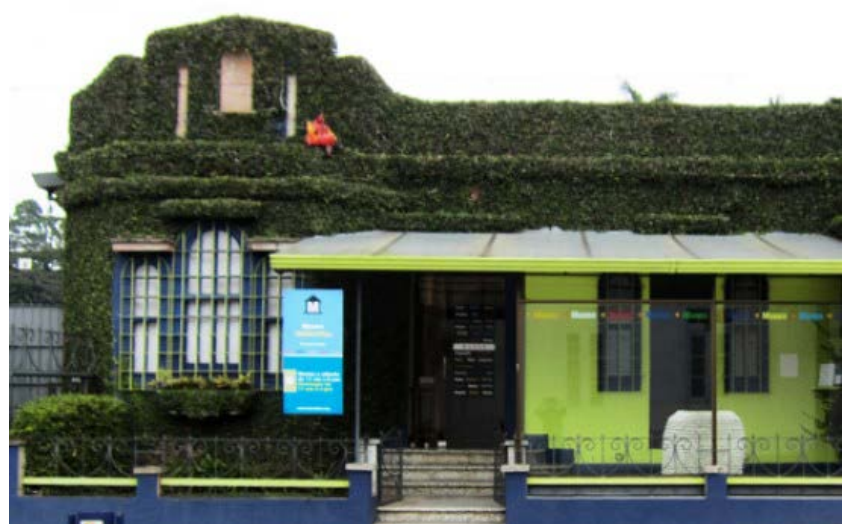

Fundación Teorética

Entre los artistas que se vinculan con este movimiento se encuentran, los guatemaltecos, Benvenuto Chavajay y Regina Galindo, y los costarricenses Priscilla Monge y Pedro Arrieta.

\section{Breve biografías}

Benvenuto Chavajay nació en 1978, en Solola. Guatemala. Estudió Artes en la Universidad de Costa Rica y ha mostrado sus obras en Estados Unidos, Brasil, Guatemala, Colombia, Bolivia, Ecuador y Costa Rica. Entre los premios obtenidos, se destacan:

- Primer premio de pintura Juannio 2008, Guatemala.

- Primer premio de pintura SEPAZ, Bolivia.

- Tercer lugar y mención honorífica Helvetas, Suiza.
Priscilla Monge nació en San José, Costa Rica, en 1968, vive y trabaja en Bélgica. Se destaca como poeta, pintora, fotógrafa, y artista conceptual, son importantes sus videos sobre la condición de la mujer, también son significativos sus performances y sus pizarras de textos repetitivos. Entre sus exposiciones más importantes están La Galería Thomas Cohn de arte contemporáneo de Rio de Janeiro, The soap factory the Athens, Grecia y ha participado en las Bienales de La Habana y Medellín, entre otras.

Regina Galindo nació en Ciudad de Guatemala en 1974, se destaca por la potencia de sus performances y videos, su trabajo artístico se caracteriza por el contenido político rescatado de su entorno, son muy conocidas internacionalmente sus denuncias hacia la invisibilidad de las mujeres, con intrevenciones violentas de su propio cuerpo y la corrupción, donde se destaca ¿Quién puede borrar las huellas?, de 2005. Recibió el León de Oro en la Bienal de Venecia, 2005 y en el 2011 ganó el Premio Principe Claus.

Pedro Arrieta. (1954-2004) fue pionero del arte conceptual en Costa Rica, sus obras son de contenido político social y lo motivó mucho la marginalidad.

\section{Conceptualización de la enseñanza desde el paradigma constructivista}

Entre los paradigmas en Psicología de la educación se destaca el psicogenético constructivista, el cual fue elaborado por Jean Piaget y desarrollado por otros grandes pensadores como Coll y Marti, Ferreiro, Teberosky, KarmiloffSmith, Doise y Mugny, Clemont, Brousseau, quienes abordan los conflictos sociocognitivos, las soluciones de problemas y contenidos, así como el análisis de la situación didáctica, plasman en sus escritos sus interpretaciones sobre el conocimiento, la enseñanza y el saber.

Toda la obra piagetniana es la epistemología, la cual se basa en las interrogantes que ya se habían planteado grandes filósofos desde Platón, Aristóteles, Descartes, Leibniz, Hume e incluso Kant, como qué es el conocimiento y cómo son los distintos tipos de saberes. Piaget se interesó mucho por resolver el tema de la adquisición 
del conocimiento en un sentido epistemológico pero desde una perspectiva genética, no de forma estática, como se había realizado por casi todos los filósofos anteriores. Para eso se tenía que observar el proceso de las transformaciones y el devenir del conocimiento, es decir, desde la infancia, además que no podía perderse de vista el plano de la hisotria del ser humano, como el plano ontogenético, de esta manera se aborda integralmente la situación del aprendizaje. Con base en esta hipótesis, aparecen otras interrogantes: cómo se construye el conocimiento científico, cómo se traslada el sujeto desde un estado de conocimiento inferior hasta otro de orden superior y cómo se originan las categorías básicas del pensamiento racional.

A partir de estas preguntas se establecen las teorías del paradigma. Aquí, el sujeto y el objeto tienen una interacción recíproca; el sujeto transforma al objeto, desde lo cognitivo, su estructura o marcos conceptuales. Si se observa con cuidado estos postulados, queda claro que el arte conceptual lleva un conocimiento inferior, el cual es el contacto primario de enfrentarse a la obra en el plano visual básico hasta un plano de análisis y reflexión para comprender su significado, desde el contenido y lo abstracto hasta lo concreto en un plano superior, cuando se superan las barreras iniciales.

\section{Algunos autores cuyas obras se refieren a aspectos de la realidad social}

En las obras de P. Monge, Lecciones de maquillaje, 2010, Museo de arte y diseño contemporáneo, la artista reflexiona, desde una postura creativa y cruel, la violencia doméstica, este tema sería más interesante analizarlo en un centro educativo si se utilizara estas obras.
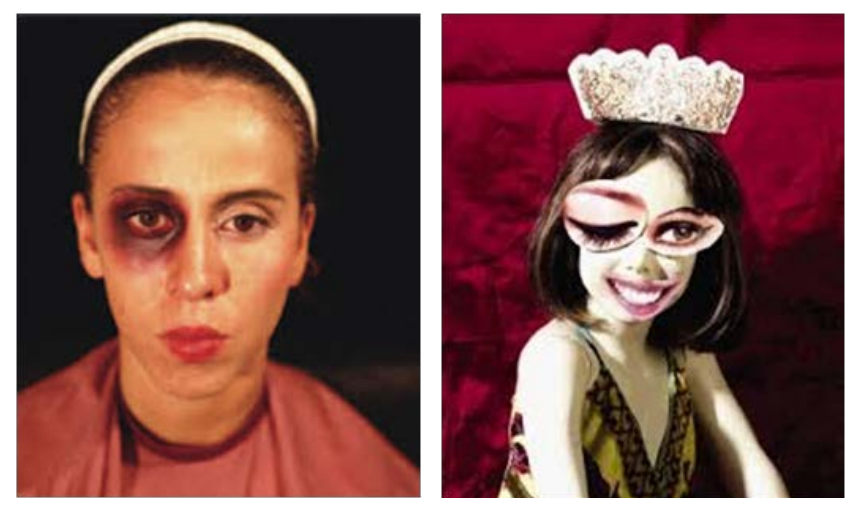

Priscilla Monge. Clases de maquillaje. 2010. Presentadas en Teorética y MADC.

Desde el contexto educativo, las ideas contenidas en el paradigma constructivista de Piaget y Vygostki "que se han puesto en práctica en distintos ámbitos educativos, en la educación preescolar, primaria, secundaria, superior, especial y hasta la moral, y en diferentes áreas del conocimiento escolar, como lo son las matemáticas, la lengua escrita, ciencias naturales y las ciencias sociales", (Montealegre, 2014). Es en eso último donde opera el objetivo de este trabajo, de acuerdo con dicho paradigma se puede utilizar el arte conceptual para comprender mejor algunas de las situaciones de orden social que han marcado la historia y la cultura, como las que plantea Regina Galindo, sobre la situación de violencia que vive Centroamérica.

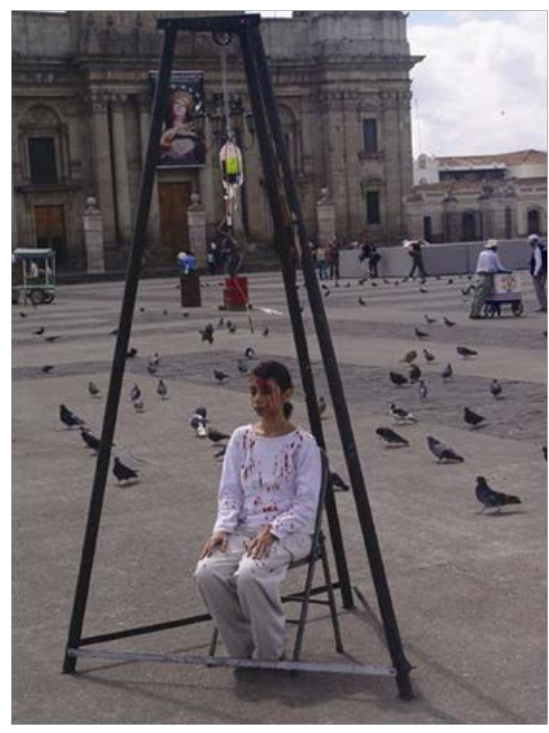

Regina Galindo. El peso de la sangre. 2015. Bienal Internacional de Asunción 
En este paradigma, la enseñanza debe utilizar métodos activos, centrados en los intereses de los educandos, en este aspecto tiene coincidencias con la corriente de la "escuela activa" desarrollada por educadores como Montessori, Ferriere, Decroly, entre otros. En el ámbito de la educación contemporánea, donde los estudiantes están expuestos a mensajes vacios y fáciles de digerir, la utilización de los nuevos lenguajes estéticos de la postmodernidad (los cuales coinciden históricamente con la elaboración de estas propuestas y nunca fueron tomados en cuenta) podrían ser válidos para aportar a una enseñanza más proactiva.

Según el paradigma constructivista psicogenético, el alumno es un constructor activo de su propio conocimiento y el reconstructor de los contenidos escolares enfrentados. Si el alumno tiene que referirse al aspecto enajenante producido por el deporte $y$, en particular, el futbol, que en muchas ocasiones permite el alejamiento o que se ignoren problemáticas más de mayor impacto social, una obra como "Futbol con denge", de Pedro Arrieta, podría ser interesante para debatir esta situación. Desde esta perspectiva, el papel del alumno deja de ser pasivo, pues construye, pero para que esto se logre debe considerse el papel del docente, el cual tiene que estimular, conducir las interrogantes del análisis hacia la producción de un resultado y un conocimiento placentero. Se pueden reforzar algunos aspectos como el paso de un análisis individual a un análisis colectivo y, desde el punto de vista operacional, añadir la cooperación y la experiencia social.

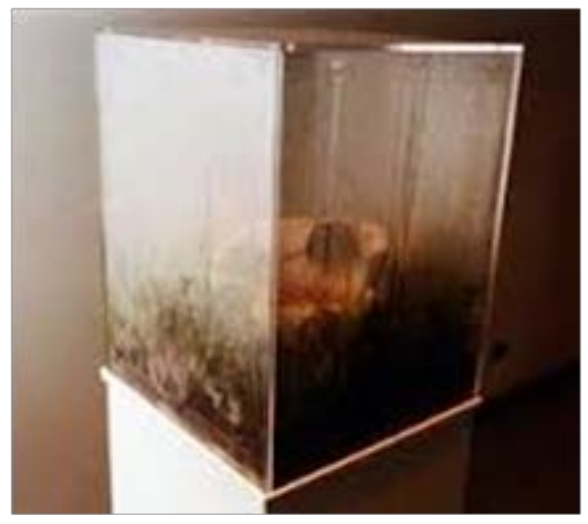

Pedro Arrieta. Futbol con denge. 1990. MAC
Desde el paradigma constructivista, la relación entre los docentes y los estudiantes no puede ser pasiva, como tampoco lo es la de los estudiantes frente a las obras de arte; los docentes tienen que "saber enseñar", pero para lograrlo tienen que actualizarse, ser abiertos y desprejuiciados, para practicar recursos educativos como la utilización del arte y, más aún, en este caso, que la propuesta es de utilizar el arte conceptual, que es poco conocido, es fundamental. Para lo cual se deben superar los prejuicios de ver el arte como "bonito", conocer las categorías estéticas, estimular a través de preguntas relacionadas, para que los estudiantes lleguen a conclusiones por si solos.

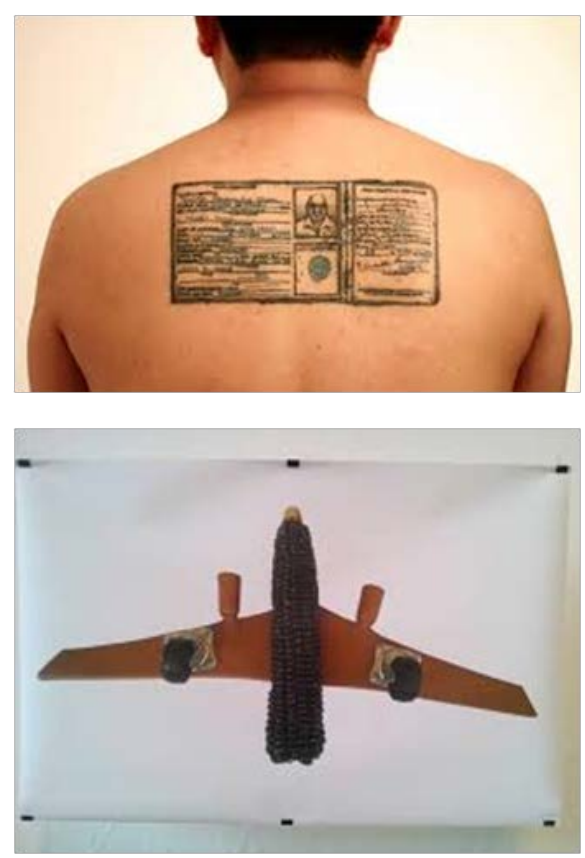

Benvenuto Chavajay. Chunches. 2015. MADC

El docente debe promover el intercambio de puntos de vistas, la independencia y abandonar viejas prácticas pedagógicas, ser creativos, dejar lo tradicional, para que sirvan también de inspiración a sus alumnos, al transmitirles confianza para que puedan expresarse sin miedo a la equivocación o al error y que esto lo sientan como una forma de aprendizaje. Es posible al utilizar obras de arte y en particular el arte conceptual, que siempre está abierto a la multiplicidad de lectura e interpretación. La serie Chunches de Benvenuto Chavajay, puede ser entendida desde la identidad, al rescatarla o contaminarla. 
El arte de conceptos permite, para la comprensión de sus contenidos, procesos mentales que van desde la exploración, la asociación, la comparación y el análisis, que no son exclusivo para el arte, sino que se incorporan a la conducta de los estudiantes. De igual manera, se puede poner en práctica elementos básicos, planteados en el paradigma sociocultural, ya que desde las teorías de L.S. Vigotsky, "a la relación bipolar del sujeto-objeto se tiene que sumar los artefactos o instrumentos socioculturales, esta propuesta le introduce un ingrediente más a las interpretaciones de la psicología de la educación, ya que entonces para que el sujeto pueda actuar sobre el objeto, tiene que utilizar instrumentos de naturaleza sociocultural" (Vargas, 2004).

De la misma manera, "así, se puede concluir que el sujeto, a través de la actividad mediada, en interacción con su contexto sociocultural y participando con los otros en prácticas socioculturalmente constituidas, reconstruye el mundo sociocultural en que vive; al mismo tiempo tiene lugar su desarrollo cultural en el que se constituyen progresivamente las funciones psicológicas superiores y la conciencia" (Hernández, 1998). Esta afirmación es de mucha importancia para este trabajo, ya que, como se ha afirmado anteriormente, el arte conceptual, tanto desde su postura conceptual como en la práctica, se manifiesta contrario a las ideologías burguesas, niilístas y narcisistas de la postmodernidad, y sus discursos están dirigidos a la toma de conciencia de los problemas socioculturales de la actualidad, así que desde este punto de vista existe coincidencia con el paradigma explicado.

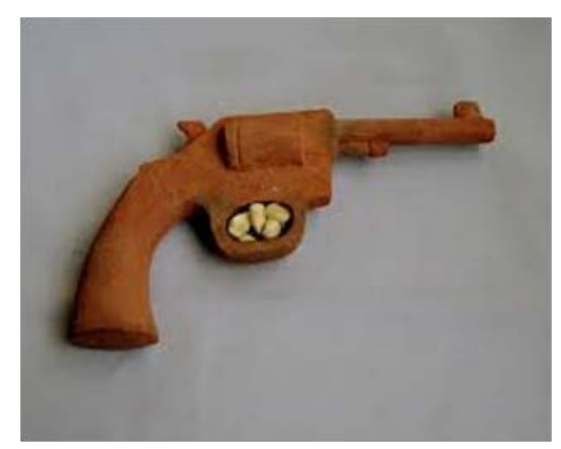

Benvenuto Chavajay. Chunches. 2015

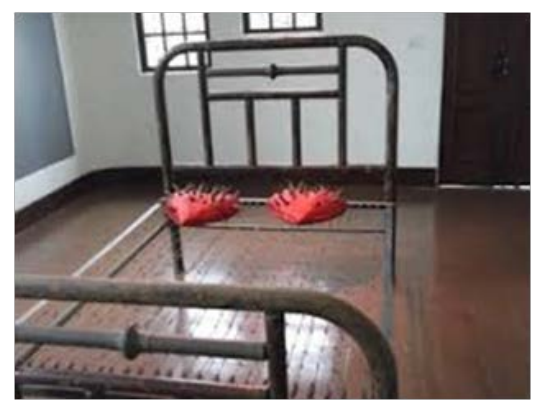

MADC, Pedro Arrieta. Amor punzante, noche tras noche.1992. MAC

Por otro lado, también es necesario señalar el papel que tienen las funciones psicológicas superiores, las cuales, según Vigotsky, solo pueden entenderse a través del estudio de la actividad instrumental mediada y se desarrollan en el contexto de las relaciones socioculturales organizadas, además del valor que esto produce en la conciencia. Se mencionan algunos de los instrumentos psicológicos, como son los sistemas numéricos, la escritura, las mnemotecnias (simples y complejas), los símbolos algebraicos, las notas musicales, los sistemas de comunicación de varios tipos (el lenguaje de las banderas, el lenguaje oral y el lenguaje de los signos, usados por el arte conceptual). Por ejemplo, en las imágenes anteriores se representa la violencia en dos versiones; en una situación de aprendizaje se puede proponer al alumnado descubrir a cuál violencia se refieren y en qué contexto.

La semiótica, como ciencia de los usos de los signos y símbolos en el arte, sirve para relacionarse entre las obras de arte y los espectadores, la decodificación de estos últimos permite que el apreciador modifique su manera de ver al objeto, se interrelacione con él y esto le permita cambiar su conducta y, de alguna manera, la conducta colectiva.

Por ot lado, en el paradigma sociocultural se le brinda importancia al componente genético y a la investigación de los procesos de constitución y su historia, al respecto, Vygostki señaló “... son muchos los que siguen interpretando erróneamente la psicología histórica. Identifican la historia con el pasado..." (Hernández, 1998). Desde el arte conceptual, esta percepción es muy válida, porque permite reflexionar acerca del componente histórico, para comprender su influencia en la propia experiencia de aprendizaje. 

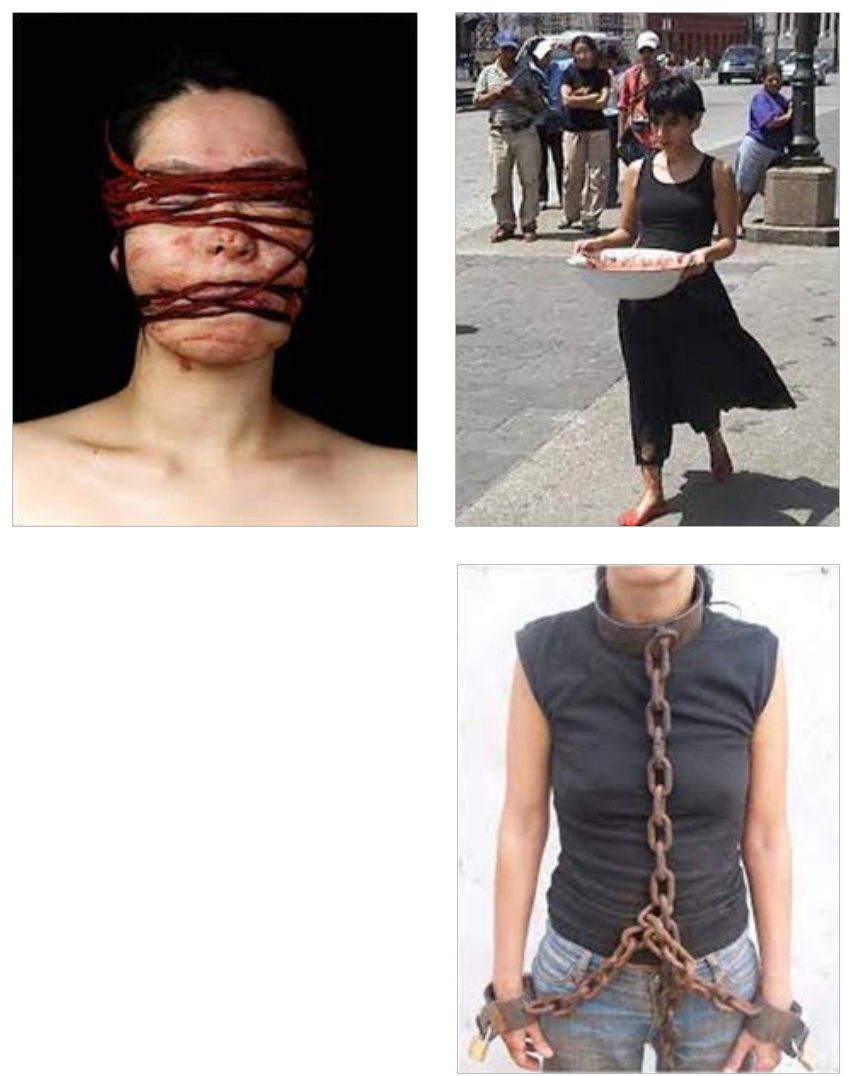

Regina Galindo. Perfomance. 2015. Guatemala

Como muestra, los trabajos de Regina Galindo no son del todo comprendidos por el público medio de Costa Rica, ya que este no ha vivido o no conoce las realidades históricas de Guatemala, plagada de violencia, discriminación, golpes de estado, etc, situación que es ajena a la realidad costarricense. Por este motivo, la educación formal debe estar dirigida, desde su concepción, a promover el desarrollo de las funciones psicológicas superiores, para llegar a un uso funcional y reflexivo, el cual considere que cada cultura proporciona a su sociedad los instrumentos necesarios para la transformación del entorno por parte de las nuevas, así como el cambio de la sociedad y de ellos mismos. Para propiciar esto, la enseñanza tiene que ser creativa, innovadora, y actualizada, por tanto, el uso de los nuevos lenguajes estéticos proporciona un ingrediente sustantivo para ejecutarlo.

En este paradigma, los educandos son comprendidos como seres sociales, desde su individualidad y su desarrollo está estrechamente vinculado con la interacción social en toda su vida, dentro y fuera de las escuelas, con sus compañeros, con los familiares y amigos, las visitas a sitios históricos y por supuesto la asistencia sistemáticas a galerías y museos. El contacto regular con el arte les permite a los estudiantes mantener una relación más familiar con este, con sus nuevas propuestas y el conocimiento que les aporta, de forma que es posible perder el miedo a lo nuevo, paso indispensable para enfrentarse al arte conceptual en sus diversas variantes. Asímismo el docente será un agente, también mediador según el punto de vista cultural, que permite al estudiante, mediante actividades estructuradas, la interactividad y promoeva la construcción de conocimiento. En este sentido se aprecian coincidencias con el constructivismo.

Se parte de la premisa de que se han elaborado variados conceptos de aprendizaje. Shuell (1997), por ejemplo, afirma qe "aprender, es un cambio perdurable de la conducta o en la capacidad de conducirse de manera dada como resultado de la práctica o de otras formas de experiencia." Desde lo filosófico, el aprendizaje, epistemológicamente, se encarga de estudiar la naturaleza, el origen, los métodos y límites de la construcción del conocimiento, al valorar interrogantes como la forma en la que se aprende, cómo se aprende algo nuevo y cuál es la guente del conocimiento. A partir de estas preguntas se determinan dos posicones sobre el origen del aprendizaje y su relación con el medio: el aprendizaje es el cambio conductual o cambio en la capacidad de comportarse o la capacidad que tiene una persona de realizar algo diferente de lo que tradicionalmente realizaba, de esta manera el aprendizaje se concreta, en la acción de romper con hábitos anteriores o modificarlos, incorporar nuevos saberes de forma consciente que el conocimiento perdure.

Finalmente, según Lyotard (1984) “...en principio el saber científico, no es todo el saber, siempre ha estado en competencia y en conflicto con otro tipo de saber, el narrativo...". En este sentido, tiene valor que se puedan utilizar otros recursos que sean válidos para adquirir aprendizaje $\mathrm{y}$ en este trabajo se propone, el arte conceptual. 


\section{Conclusiones}

En este trabajo queda demostrado el valor que tiene el arte como un elemento importante de la cultura, ya que el arte en sí es cultura. En la postmodernidad globalizada, los intereses hegemónicos recetan una cultura masificada, donde los individuos partícipes de esta sociedad estám al servicio de las estructuras económicas que inducen al consumo, a digerir mensajes fáciles de decodificar, donde pensar está prohibido.

Los Estados neoliberales contemporáneos han mercantilizado el saber y el conocimiento se produce en dependencia de los beneficios económicos posibles, el saber se estimula y se produce para ser vendido, consumido y reinventado para volver a venderse. Las nuevas tecnologías en vez de acercar más al conocimiento, aleja a as personas de este, de manera que se convirerten en analfabetas informados. En este sentido la cultura y el arte están al servicio de los aspectos más banales de la vida, se premia a lo "sin sentido"; niños y jóvenes pasan horas conectados a redes que no son sociales, a pesar de es posible conectarse con otros.

Los medios de comunicación masiva abogan por la libertad de expresión (que no practican), informan lo que ideológicamente es correcto para los mecanismos de poder, aquello que no altere la dinámica del engranaje, donde las personas son solo piezas, se miden estas por el capital que han acumulado y el éxito se alcanza por lo abultado de las cuentas bancarias, individuos que tienen más dinero que el producto interno bruto de muchos países, y se hacen rankins de las personas más adineradas del mundo, mientras los niveles de pobrezas en el mundo es alarmante y ofensivo, ante tanto derroche. Los porcentajes de niños sin educación se eleva, porque los niveles de deserción son escalofriantes, niños que prefieren trabajar.¿De qué sirve dotar de internet a los pobres? Internet sin educación? Su misión es la enajenante, no hay derecho ni al enojo.

En esta dramática realidad, todavía se considera al arte como un medio para el entretenimiento que permite aislarse y rendir culto a gente ajena al contexto inmediato. in embargo, existen artistas, $y$ por suerte muchos, cuyas obras están destinadas a contar aquellas situaciones que los medios controlados no cuentan, artistas comprometidos con los problemas culturles, quienes pretenden darle voz a los sin voz, con una actitud vanguardista, bajo una estética realista, basado en una actitud comprometida y de acción, pero estos contadores de historias, denunciantes, contestatarios, son a menudo desconocidos en su propio mundo.

El arte conceptual, en su versión latinoamericana, está muy vinculado discursivamente con las problemáticas sociales, es el reflejo de las luchas, y vivencias. La educación es marcadamente instructiva, desaprovecha las posibilidades ofrecidas por el arte, el desconocimientos de los nuevos lenguajes estéticos no ha permitido incorporarlos como recurso educativo, para la motivación de una clase o incluso para la comprobación de un contenido.

En este trabajo, se han utilizado argumentos teóricos del paradigma constructivista, teorías del aprendizaje, postulados filosóficos, sin abandonar los componentes socioculturales en la historia y en la postmodernidad. Autores como Piaget, Vigostky, Lyotard, Hernandez, Shunk, entre otros, al final coinciden en el papel creativo del maestro para lograr un aprendizaje significativo, entonces uno de los recursos que se pueden incorporar es el arte y en particular el arte conceptual, por su discurso y actualidad. A través de cuatro exponentes del arte centroamericano, se ejemplificó cómo sus obras y la de otros pueden ser objetos de estudio para comprender el mundo. 


\section{Referencias}

Abbagnano, N. y Visalberghi, A. (1992). Historia de la Pedagogía. Fondo de Cultura Económica. Novena reimpresión. México.

Bautista Vallejo, José. (2006). Educar en la postmodernidad. San José. Costa Rica. Editorial UNED.

Bazin. G. (1998). Historia del arte, de la prehistoria a nuestros días. Editorial Omega. Sétima edición. Barcelona. España.

Bernardini, Amalia y Soto,José A.( 1993). La educación actual en sus fuentes filosóficas. San José. Costa Rica. Editorial UNED.

Buletti, S. (2015). El uso de imágenes en la enseñanza de la historia: Reflexiones y propuestas. VIII Jornadas Nacionales y $1 \mathrm{er}$ Congreso Internacional sobre la Formación del Profesorado. Facultad de Humanidades. Universidad Nacional de Mar del Plata. Argentina.

Blakemore y Frith.( 2007). Como aprende el cerebro. España. Editorial Planeta. s.a.

Hernández, Gerardo. (1998). Paradigmas en psicología de la educación. México.DF. Editorial Paldós Mexicana.

Kuhn, T. (2004). La Estructura de las Revoluciones Científicas. Fondo de Cultura Económica. México.

Leake, M. D. (2014). “Social Engagements with Contemporary Art: Connecting Theory with Practice". Art Education, 67(5), 23-30. Compromisos sociales y arte contemporáneo: Conectando la teoría con la práctica.

Lyotard, Jean. (1984) La condición postmoderna. Madrid. España. Ediciones Cátedra.
Montealegre. Rosalia. (2014). Controversias PiagetVygostki en psicología del desarrollo. Bogotá. Editorial U.N.C.,

Morin, Edgar.(1999). La cabeza bien puesta. Buenos Aires. Argentina. Editorial Nueva Visión.

Muñoz, L. y Ruiz, G. (2003). “El arte de enseñar a través del arte: el valor didáctico de las imágenes románicas”. Educatio, n. ${ }^{\circ}$ 20-21. Diciembre.

Schunk, Dale. (1997). Teorías del aprendizaje. México. DF. Pearson Educación.

Vargas A. (2004). Constructivismo, fenomenología y educación: un análisis de paradigmas en psicología. España. U.L. 
